\title{
Os (Des) Caminhos do Ensino de Espanhol no Brasil
}

\author{
Los (Des) Caminos de la Enseñanza de Español en Brasil
}

\author{
Luciana Contreira Domingo ${ }^{1}$ \\ 1ludomingo@gmail.com, Universidade Federal do Pampa.
}

\begin{abstract}
Resumo
Traçar o percurso realizado pela Língua Espanhola no sistema educacional brasileiro é, senão uma tarefa difícil, pelo menos surpreendente. Neste trabalho refletiremos sobre o caminho percorrido pelo idioma espanhol no Brasil. Para tentar compreender a forma como o sistema educativo brasileiro entende o ensino de espanhol em nosso território, analisaremos neste trabalho os movimentos em relação à oferta do idioma na educação básica do país e alguns desdobramentos das principais ações levadas a cabo até o momento. Para mapear o caminho, focaremos quatro momentos compreendidos entre o ano de 1942 até a atualidade. Nossa reflexão aponta que, apesar dos esforços realizados na elaboração de uma proposta de inserção deste idioma no sistema educacional brasileiro, ainda não conseguimos construir uma política linguística sólida que atenda as especificidades do ensino desse idioma em nosso país.
\end{abstract}

Palavras-chave: ensino regular, espanhol, documentos nacionais, educação básica, política linguística.

\section{Resumen}

Trazar el recorrido realizado por la Lengua Española en el sistema educativo brasileño es, si no una tarea difícil, por lo menos sorprendente. En este trabajo reflexionaremos sobre el camino recorrido por el idioma español en Brasil. Para intentar comprender la forma como el sistema educativo brasileño entiende la enseñanza de español en nuestro territorio, analizaremos en este trabajo los movimientos relativos a la oferta del idioma en la educación básica del país y algunas consecuencias de las principales acciones llevadas a cabo hasta el momento. Para mapear el camino, destacaremos cuatro momentos comprendidos entre el año 1942 hasta la actualidad. Nuestra reflexión señala que, pese los esfuerzos realizados en la elaboración de una propuesta de inserción de este idioma en el sistema educativo brasileño, todavía no hemos logrado generar una política lingüística sólida que atienda las especificidades de la enseñanza de este idioma en nuestro país.

Palabras clave: enseñanza reglada, español, documentos nacionales, educación básica, política lingüística.

\section{Primeiras palavras: "Del dicho al hecho hay mucho trecho"}

A tarefa de construir um ensino de línguas de qualidade não será fácil porque o poder ideológico é subjugado pelo poder político, que por sua vez é dominado pelo poder econômico de produção. Sendo o poder exercido pelas classes dominantes com o objetivo de obter determinadas vantagens, pode-se concluir que a exigência de oferecer línguas estrangeiras no ensino fundamental e médio vem ao encontro dos interesses do poder econômico e é considerado importante para a preservação do Estado. Os aspectos educacionais e culturais e a socialização deste ensino para todos os alunos serão, no entanto, objetivos difíceis de perseguir (BOHN, 2000, p. 132). 
O desafio sugerido por Bohn na epígrafe acima indica que qualificar a educação da linguagem e o sistema educativo em geral requer, entre outras muitas ações, investimentos na formação inicial e continuada, mas a qualidade desse sistema só aumentará efetivamente se sujeitos, agentes e contextos puderem enfrentar de maneira crítica discursos autoritários e essencialistas, construídos ao longo de séculos de colonização, que revelam posturas ideológicas e interesses políticos que os afetam diretamente, seja na formação inicial e continuada ou em suas práticas profissionais.

Em congruência ao apontado por Bohn (2000, p. 132), a consideração do contexto mutante, híbrido e globalizado em que vivemos é condição fundamental para a mudança social que só uma educação libertadora, em termos freireanos (FREIRE, 2009), é capaz de proporcionar. Entretanto, currículos descontextualizados que denotam ausência ou ineficiência de políticas linguísticas e culturais, livros didáticos selecionados para sujeitos silenciados que, definitivamente não se identificam com o material e programas e exames de avaliação nacional que desconsideram as individualidades, subjetividades e o contexto sócio histórico de cada região - em claras tentativas de homogeneização - atestam que ainda não aprendemos a lidar com a liquidez/ volatilidade de nosso tempo.

Para tentar compreender a forma como o sistema educativo brasileiro entende o ensino de espanhol em nosso território, analisaremos neste trabalho os movimentos em relação à oferta do idioma na educação básica do país e alguns desdobramentos das principais ações levadas a cabo até o momento. Para mapear o caminho, focaremos quatro momentos compreendidos entre o ano de 1942 até a atualidade.

\title{
2. Mapeando o caminho
}

\begin{abstract}
Mais de uma vez o Espanhol esteve presente como disciplina em nossas escolas, porém essa nunca esteve tão claramente associada a um gesto marcado de forma inequívoca por um objetivo cultural, político e econômico, uma vez que a LDB prevê a possibilidade de oferta de mais de uma língua estrangeira, sem nenhuma outra especificação. É fato, portanto, que sobre tal decisão pesa um certo desejo brasileiro de estabelecer uma nova relação com os países de língua espanhola, em especial com aqueles que firmaram o Tratado do Mercosul (BRASIL, 2006, p. 127).
\end{abstract}

Nesta seção destacamos quatro momentos no que se refere à oferta do idioma espanhol na educação básica brasileira: a Reforma Capanema, em 1942, a assinatura do Tratado do Mercosul, em 1990, a Lei de Diretrizes e Bases (LDB) nº 9.394, de 1996 e a 
promulgação da Lei 11.161, em 2005. Poderíamos destacar muitos outros, como as LDBs de 1961 e 1971, no entanto, entendemos que os momentos privilegiados são mais significativos para os objetivos deste trabalho.

Em 9 de abril de 1942, Gustavo Capanema, ministro da Educação e Saúde à época, incluiu a língua espanhola como disciplina obrigatória no ensino secundário, através da Lei Orgânica - Decreto $n^{\circ} 4.244$ - correspondente a este nível. Nessa época, a disciplina tinha oferta obrigatória no $1^{\circ}$ ano dos Cursos Clássico ou Científico, ainda que com carga horária reduzida em comparação às demais línguas oferecidas. Segundo Celada (2002, p.77), com esta reforma o espanhol era oferecido durante um ano no nível secundário juntamente com o francês e o inglês, oferecidos durante dois anos.

O ano de 1990, com a assinatura do Tratado do Mercosul, entre Argentina, Brasil, Paraguai e Uruguai, parecia ser o início da consolidação da oferta desse idioma em nosso sistema educativo. Entretanto, não houve nenhum avanço significativo em termos de institucionalização do ensino, pese às relações com os países hispano-falantes que, além da assinatura do Tratado anteriormente mencionado, viu-se intensificada devido à chegada de inúmeras empresas espanholas no país a partir dos anos 90 .

Ainda na década de 90, tivemos novamente notícias sobre o ensino de espanhol na escola regular brasileira com a lei $\mathrm{n}^{\circ}$ 9.394, da $\mathrm{LDB}^{1}$, que versava sobre a oferta obrigatória, a partir da quinta série do ensino fundamental, de pelo menos uma língua estrangeira. Textualmente, o artigo 26, $\S 5^{\circ}$, estabelece que "será incluída uma língua estrangeira moderna, como disciplina obrigatória, escolhida pela comunidade escolar, e uma segunda, em caráter optativo, dentro das possibilidades da instituição" (BRASIL, 1996, p. 11). Para o ensino médio, o mesmo documento dispõe, no artigo 36, § III, que "será incluída uma língua estrangeira moderna, como disciplina obrigatória, escolhida pela comunidade escolar, e uma segunda, em caráter optativo, dentro das possibilidades da instituição" (p.14).

A produção acadêmica sobre este tema aponta um, aparente, eterno ir e vir da oferta deste componente no ensino regular brasileiro. Matos (2005, p. 9), sugere uma possível indiferença linguística por parte dos brasileiros em relação ao espanhol; outra razão apresentada pelo mesmo autor aponta o relativo isolamento linguístico e cultural no qual vivemos. Nesse sentido, Arnoux (2010) sugere que para implementar políticas de sensibilização é importante considerar as representações associadas às línguas, razão pela qual as políticas linguísticas devem estar associadas a políticas culturais.

\footnotetext{
${ }^{1}$ A terceira LDB foi promulgada em 1996, a segunda em 1971 e a primeira em 1961.
} 
Em 5 de agosto de 2005 foi sancionada a Lei 11.161, popularmente conhecida como Lei do Espanhol, versando sobre a oferta obrigatória pela escola e matrícula facultativa para o aluno no ensino médio. A implantação dessa lei foi progressiva desde 2005 ficando sob a responsabilidade dos Conselhos Estaduais de Educação, tendo como prazo final para a oferta pelos estados o mês de agosto de 2010. Nesse período observou-se uma movimentação intensa por parte de associações de professores e docentes que atuam em inúmeras universidades do país e, também, por parte de instituições estrangeiras, destacadamente as espanholas. Muito se alardeou em torno à referida lei e à quantidade de profissionais que, imaginava-se, seria necessário para atendê-la, repercutindo, inclusive, na imprensa internacional.

De 2006 a 2010 observamos uma discussão interessante em torno à Lei 11.161: inúmeros seminários, simpósios e congressos tiveram como tema o debate sobre a oferta e o ensino de espanhol, incluindo a criação de uma Comissão Permanente de Acompanhamento da Implantação do Espanhol no Sistema Educativo Brasileiro (COPESBRA) e de uma Plataforma ${ }^{2}$ para acompanhamento dessa implantação. Durante algum tempo esse espaço virtual permitiu acompanhamento da discussão sobre a problemática, divulgação de concursos públicos e eventos relacionados ao ensino do idioma, divulgação de abaixo-assinados organizados pelas Associações Regionais de Professores de Espanhol, notícias sobre movimentos de expansão do espanhol no Brasil ${ }^{3}$, etc.

Um relato interessante sobre a situação vivenciada no estado de São Paulo é realizado por Fanjul (2010) sobre a "(não) introdução do espanhol na escola pública paulista" [sic]. Em seu estudo, o autor analisa o tratamento dado pelo poder público à questão, relacionando-o a uma tendência pelo ensino de inglês e à presença de grupos privados na gestão educativa daquele estado - situação para a qual Bohn ${ }^{4}$ já alertava no ano 2000 (p.118). O relato de Fanjul parece-nos especialmente interessante porque o estado de São Paulo habilita professores de espanhol há mais de 50 anos, contando, segundo o autor, com recursos humanos suficientes para que se cumpra a lei. Entre os muitos argumentos apresentados no estudo, chamam a atenção dois aspectos: a indiferença da Secretaria Estadual de Educação diante das tentativas de diálogo e propostas apresentadas pela Associação de Professores de Espanhol do Estado de São Paulo (APEESP) no intuito de incluir o idioma nos currículos

\footnotetext{
${ }^{2}$ Disponível em: <https://espanholdobrasil.wordpress.com/> Acesso em: 20 fev. 2015

${ }^{3}$ Disponível em: <http://movimentodeexpansaodoele.blogspot.com.br/>. Acesso em: 20 fev. 2015.

${ }^{4}$ Ao analisar aspectos políticos de uma política de ensino de línguas e literaturas estrangeiras o referido autor chama a atenção para o perigo de as autoridades "venderem" a aprendizagem da língua estrangeira para organizações comerciais privadas (BOHN, 2000, p. 118).
} 
escolares, bem como responsabilizar-se pela formação inicial e continuada dos docentes; e a tentativa de outorgar a responsabilidade pela formação inicial e continuada a grupos privados espanhóis, denotando a falta de diálogo entre a academia paulista e a Secretaria de Educação. Ambos classificam-se como questões de política linguística, ou melhor, a falta dela.

Ainda com relação às consequências causadas pela Lei 11.161, acreditamos que o gesto mais concreto, por parte do Ministério da Educação e da Secretaria de Educação Básica, em relação à efetiva inserção da língua espanhola em nosso currículo escolar foi a inclusão do capítulo intitulado Conhecimentos de Espanhol, juntamente com o capítulo Conhecimentos de Linguas Estrangeiras, nas OCEM em 2006. Até esse momento, os documentos nacionais (LDB, PCN) referiam-se ao ensino de LE de forma genérica ${ }^{5}$ sem considerar as especificidades de cada idioma ou das inúmeras realidades existentes em cada região.

Nossa reflexão sobre as diferenças existentes entre ensinar uma LE na escola de ensino regular e em cursos livres parte, por um lado, de nossa experiência em ambos os níveis e, por outro, da opinião de Almeida Filho ao afirmar que:

[...] a aula de língua estrangeira como um todo pode possibilitar ao aluno não só a sistematização de um novo código linguístico que o ajudará a se conscientizar do seu próprio processo, mas também a chance de ocasionalmente se transportar para dentro de outros lugares, outras situações e pessoas. (ALMEIDA FILHO, 2002, p.28)

Obviamente essa sistematização ocorre nos dois âmbitos, escolar e livre. No entanto, ambos guardam especificidades que determinam ou deveriam determinar o fazer pedagógico. O ensino de uma LE na escola regular - de nível fundamental e médio - tem como objetivo a formação de cidadãos - daí a importância do diálogo entre essa e as demais disciplinas do currículo - para além das preocupações linguísticas e instrumentais observadas nos cursos livres. Segundo as OCEM (2006, p.130), uma disciplina não se fecha em si mesma, devendo interagir com todas as demais, ou seja, o ensino de uma LE na escola, seja de nível fundamental ou médio, tem caráter formador e educativo, como os demais componentes curriculares. Para Jorge (2009, p.163), o caráter educativo do ensino de uma língua LE encontra-se nas várias possibilidades que o aluno pode ter de se tornar mais consciente da diversidade que constitui o mundo.

Entendemos, então, que a diferença está, em grande medida, nos objetivos, nem

\footnotetext{
${ }^{5} \mathrm{O}$ art. $26, \S 5^{\circ}$ da LDB 9394/96 dispõe que "na parte diversificada do currículo será incluído, obrigatoriamente, a partir da quinta série, o ensino de pelo menos uma língua estrangeira moderna, cuja escolha ficará a cargo da comunidade escolar, dentro das possibilidades da instituição".
} 
sempre claros, deste ensino. Almeida Filho (2002) aponta para uma distorção por parte de pais e alunos com relação aos objetivos da inclusão desse componente curricular e das reais possibilidades de "sucesso" dessa oferta tendo em conta o contexto escolar (carga horária limitada, falta de material didático, salas de aula adequadas ao aprendizado de idiomas, etc.) o que, sem dúvida, compromete a credibilidade desse ensino. Sobre a falta de objetivos e suas consequências, o autor afirma que:

Historicamente, perpetuados pela tradução e refletidos nas curvas caprichosas da lei, encontramos objetivos indefinidos como metas a serem perseguidas pelo conjunto das escolas e, quando mencionados nos documentos, vê-se a sua natureza irreal e esfacelada nos pontos gramaticais que ordenam os programas de curso. Outras vezes, objetivos confusos para o ensino da língua estrangeira na escola básica contribuem para o embaçamento da questão pública do ensino das línguas. Como produto dessas distorções na área de objetivos aponta-se um ensino de idiomas no cotidiano escolar sem um mínimo de eficácia (ALMEIDA FILHO, 2007, p.39).

A situação descrita por Almeida Filho dialoga com a análise de Rodrigues (2010, p.107), que afirma que os discursos das LDBs de 1971, 1976 e 1996, que identificam as línguas estrangeiras com conteúdos que podem ser trabalhados de maneira extracurricular, contribuíram e continuam contribuindo com um processo de desoficialização ${ }^{6}$ dessa disciplina, colaborando para sua desvalorização enquanto parte integrante do currículo escolar. Segundo a autora, essa desvalorização contribui para a disjunção língua de mercado e língua da escola e alimenta o imaginário de que LE não se aprende na escola. Em sua análise da LDB de 1996, inciso IV do artigo $24^{\circ}$, Rodrigues destaca a dissociação do estudo de línguas estrangeiras das demais matérias do currículo, presente explicitamente em: "Poderão organizar-se classes, ou turmas, com alunos de séries distintas, com níveis equivalentes de adiantamento na matéria, para o ensino de línguas estrangeiras, artes, ou outros componentes curriculares" (LDB, 1996, p.13). A autora afirma ainda que no imaginário que circula no Brasil há a LE da escola, caracterizada pela facilidade, falta de compromisso e de qualidade e a LE dos cursos livres, associada ao sucesso, utilidade, etc.

[...] no nível do imaginário que circula no Brasil, podemos afirmar que, por um lado, há uma língua estrangeira da escola - cujos sentidos atribuídos aos conteúdos ensinados entram em relação com escassez, desimportância, inutilidade, enquanto que os sentidos atribuídos ao processo de aprendizagem nesse âmbito entram em relação com fracasso, ineficácia e esquecimento -; por outro lado, há uma língua estrangeira dos cursos livres - cujos conteúdos entram em relação com necessidade

\footnotetext{
${ }^{6}$ Grifo no original.
} 
real, uso efetivo, eficácia do conhecimento adquirido, enquanto que o processo de aprendizagem nesse âmbito traz sentidos que se relacionam com prazer, ausência de esforço, pragmatismo, sucesso (RODRIGUES, 2010, p. 106).

Essa reflexão "justifica", de certa forma, o descrédito que goza o ensino de línguas estrangeiras nas escolas regulares e o prestígio dos cursos livres, que em alguns casos estão dentro das escolas oferecendo um "serviço" terceirizado, como os centros de idiomas presentes em muitos estados brasileiros. O próprio documento aponta a fragilidade observada no ensino de idiomas:

Verifica-se que, em muitos casos, há falta de clareza sobre o fato de que os objetivos do ensino de idiomas em escola regular são diferentes dos objetivos dos cursos de idiomas. Trata-se de instituições com finalidades diferenciadas. Observa-se a citada falta de clareza quando a escola regular tende a concentrar-se no ensino apenas linguístico ou instrumental da Língua Estrangeira (desconsiderando outros objetivos, como os educacionais ou culturais). Esse foco retrata uma concepção de educação que concentra mais esforços na disciplina/ conteúdo que propõe ensinar (no caso, um idioma, como se esse pudesse ser aprendido isoladamente de seus valores sociais, culturais, políticos e ideológicos) do que nos aprendizes e na formação desses. A concentração em tais objetivos pode gerar indefinições (e comparações) sobre o que caracteriza o aprendizado dessa disciplina no currículo escolar e sobre a justificativa desse no referido contexto (BRASIL, 2006, p. 90).

O segundo aspecto das OCEM - Conhecimentos de Espanhol - que optamos por destacar neste trabalho refere-se à heterogeneidade do espanhol (2006, p. 134), numa clara referência à diversidade cultural e linguística do idioma, sobre a qual muitas vezes pesa um profundo desconhecimento que remonta às relações entre as Américas Espanhola e Portuguesa:

Há, contudo, o obstáculo da dissociação histórica entre as américas portuguesas e espanhola, as dificuldades crônicas e cíclicas nos processos de desenvolvimento dos nossos países e, se não houver planejamento à altura da vontade política, a introdução unilateral da língua espanhola no currículo brasileiro por si só não será capaz de atender as expectativas de isonomia a longo prazo (ALMEIDA FILHO, 2007, p. 46).

No Brasil, o descompasso nessas relações contribuiu à criação de um discurso sobre os países hispano-americanos, sua gente e sua cultura, com consequências na maneira como o brasileiro se relaciona com o idioma. Pizarro afirma que nosso desconhecimento mútuo entorpece as relações: 
O estudo das relações entre a América hispânica e o Brasil é um campo de intercâmbios sugestivo que nos abre à compreensão de nós mesmos. Além da dinâmica geral da relação, das vinculações estruturais, do imaginário - de um em relação ao outro desde o período colonial -, por meio de um terceiro ponto, como tem sido a Europa para os Estados Unidos, casos concretos revelam como este desconhecimento entre os blocos culturais tem entorpecido nosso estudo e nossa compreensão (PIZARRO, 2006, p.57).

O desconhecimento da imensa variedade cultural e linguística do idioma espanhol nos faz pensar que a "clássica e falsa dicotomia espanhol peninsular e variedades hispanoamericanas" (OCEM, 2006, p. 134), revela também um desconhecimento da imensa variedade cultural e linguística do Brasil. Talvez tenhamos que aprender a valorizar e respeitar nossas próprias diferenças para, então, respeitar e valorizar as diferenças alheias; por outro lado, esse debate leva-nos a outro, igualmente interessante, em torno à(s) identidade(s) cultural(ais) construídas a partir da diferença com base no que Hall (2011, p. 16) denomina como efectos de frontera: Necesita lo que queda afuera, su exterior constitutivo, para consolidar el proceso.

Desconhecer, ignorar são ações extremamente úteis a sistemas de governo que produzem sentidos simultaneamente em diferentes níveis: o do discurso e o da prática. No nível do discurso observa-se o estímulo à construção de uma identidade compartilhada identidade latino-americana - necessária ao bom entendimento e à convivência pacífica. Nesse discurso, presente em muitos documentos orientadores da educação nacional, evidencia-se a irmandade dos povos e, em alguns casos, a origem comum - a raiz latina - dos idiomas português e espanhol. Na prática, o discurso desvanece, evidenciando uma lógica presente na epígrafe de Bohn (2000, p. 132) que abre este trabalho: a dependência de interesses políticos, econômicos e ideológicos. O que observamos em nossa prática como docente na educação básica e superior é o incumprimento do disposto nos discursos dos documentos oficiais, dos acordos bilaterais entre os países da região, da própria LDB. Sabemos, entretanto, que essa desatenção atende aos objetivos de uns poucos a quem uma relação intercultural pautada pelo conhecimento, pela construção de saberes conjuntos e pelo diálogo não interessa. Bauman sintetiza claramente o poder exercido pelo conhecimento:

Todo conocimiento es una visión ordenada, una visión del orden y por ello contiene una interpretación del mundo. No refleja, como creemos a veces, las cosas tal como son en sí mismas; sucede más bien que las cosas son engendradas por el conocimiento que tenemos. Es como si nuestras sensaciones crudas y rudimentarias se condensaran en cosas volcándose en los recipientes que nuestro conocimiento ha preparado para ellas en forma de categorías, clases, tipos. Mientras más conocimientos tenemos, más cosas vemos, más cosas diferentes discernimos en el 
mundo. Decir "tengo más conocimiento" y "distingo más cosas en el mundo" son dos aseveraciones que significan lo mismo (...) La diferencia entre una persona ignorante en arte y un experto, ya sea un artista o un crítico, se manifiesta en primer lugar en la capacidad de la primera persona para ver los colores que para la segunda se presentan agresiva y naturalmente separados. $Y$ puede expresarse también en el hecho de que la segunda persona pierda la capacidad de ver lo "rojo" como tal, de percibir todos los objetos pintados con diversos matices de rojo como si fueran el mismo color (BAUMAN, 1994: 227-228).

Engajar-se nas ações políticas de planejamento e execução de programas voltados ao desenvolvimento da educação da linguagem requer, como mínimo, conhecimento e capacidade de articulação desse conhecimento com a(s) realidade(s) brasileira. Refazer o percurso percorrido na tentativa de inclusão do idioma espanhol em nosso sistema educativo, da década de quarenta aos dias de hoje, refletir sobre a formação de mediadores interculturais e propor alternativas às propostas defasadas, porque descontextualizadas e homogeneizantes expressa nossa tentativa de engajar-nos propositivamente nessas ações.

Nossa concepção de ensino-aprendizagem de idiomas aponta para a estreita relação entre os pontos destacados da leitura do texto Conhecimentos de Espanhol (OCEM, 2006). Acreditamos que a falta de clareza dos objetivos para o ensino de línguas estrangeiras na educação básica, através de uma política linguística séria e comprometida somente ou principalmente com a formação de cidadãos de um mundo "permanentemente cambiante" (OCEM, 2006, p. 129), alimenta a crença de que não é possível aprender línguas na escola. Por outro lado, essa crença alimenta outras, tais como a da superioridade de uma variedade sobre outra (e consequentemente, de um povo sobre outro) e a espontânea facilidade dos brasileiros para o aprendizado do espanhol.

Nosso olhar restringiu-se, nesse momento, a pontos relacionados ao trabalho ao qual nos dedicamos. No entanto, acreditamos que a leitura crítica e discussão desse documento nacional de orientação curricular (que representa, conforme já apontamos, o primeiro gesto concreto no sentido de pensar a oferta do idioma espanhol em nosso sistema educativo), bem como dos demais documentos citados neste trabalho, deveriam fazer parte de todos os cursos de formação de professores em nosso país. Só assim poderemos desconstruir mitos, ou, para ser menos utópicos, construir bases mais sólidas para o ensino de espanhol no Brasil atendendo as especificidades de cada região e as relações já existentes - ou não - com esse idioma.

Apesar das inúmeras menções à proximidade dos idiomas português e espanhol, ao papel da língua materna no processo de aprendizado de espanhol e à fronteira do Brasil com países hispano-falantes - Argentina, Paraguai e Uruguai, especificamente citados pelo 
documento, as Orientações não consideram as especificidades de ensinar e aprender outra língua em região fronteiriça. Essa ausência também é observável em outras propostas, como o Programa Nacional do Livro Didático (PNLD), LDB, PCN (1998 e 1996), Diretrizes Curriculares Nacionais para os Cursos de Letras (Parecer CNE/ CES 492/ 2001) e também em documentos regionais como o Referencial Curricular Lições do Rio Grande (2009). Esse silenciamento desconsidera também as especificidades de cada região e o contato das mesmas com países hispano-falantes. Curiosamente, todos destacam o papel das línguas estrangeiras na constituição dos sujeitos a partir do contato e da exposição ao diferente.

Sobre essa ausência também podemos inferir que a mesma dificulta o processo de desestrangeirização da língua estrangeira como propõe Almeida Filho (2002, p. 12). Para o autor, a língua só é estrangeira a princípio, desestrangeiriza-se ao longo do tempo de aprendizagem. Nesse processo, a língua aprendida para e na comunicação, é construída pelo aprendiz, que também a constrói.

Certamente, a presença do idioma espanhol em nosso sistema educativo - sem relação com o português brasileiro e, por consequência, sem vínculo com aspectos históricos e sócio-culturais com os países da Latino América - se viu afetada por esse tratamento homogêneo dispensado por inúmeros documentos nacionais. A condição fronteiriça com sete países hispano-falantes (Argentina, Bolívia, Colômbia, Paraguai, Peru, Uruguai e Venezuela) parece não ter sido determinante, nem ao menos motivadora para a inclusão do ensino do espanhol no sistema educativo brasileiro. Apesar dessa constatação pouco animadora sobre o lugar da língua espanhola no sistema educativo brasileiro, Arnoux (2014) vislumbra aspectos positivos a respeito de uma possível integração sul-americana em uma discussão sobre glotopolítica:

En el caso sudamericano, los movimientos respecto de la integración regional han implicado avances significativos de los cuales el de mayor envergadura, si valorizamos los espacios de participación ciudadana y constitución política, es la Unión de Naciones Suramericanas, Unasur, establecida a partir del Tratado Constitutivo de 2008 entre todas las repúblicas que integran este continente. Lo precedieron y/ o conviven con él el Pacto Andino (1969); el Acta de Iguazú (1985), acuerdo bilateral entre Brasil y Argentina, y el Tratado de Asunción (1991), que sienta las bases del Mercosur integrado por Argentina, Brasil, Paraguay, Uruguay y Venezuela. Unasur afirma su voluntad de incidir en las transformaciones sociales necesarias para construir una democracia participativa (ARNOUX, 2014, p.15).

Os objetivos dessa União, construir uma identidade e cidadania sul-americanas, ainda não surtiram efeito nos documentos que orientam a educação brasileira, tal qual 
comprovamos nos documentos citados nesta seção. A construção de uma identidade comum, em termos de continente, pressupõe considerar a situação linguística das sociedades em questão, incluindo práticas, ideologias, representações, etc. No caso da língua espanhola em regiões de fronteira com países hispanos, essa consideração implica um passado, um presente e, consequentemente, um futuro histórico e cultural comuns. Como elaborar propostas didáticas, projetos de política linguística ou planejamento profissional docente para regiões fronteiriças? Como desenvolver uma identidade comum e uma consciência cidadã que promova o progresso social obviando a relação língua-cultura na constituição dos sujeitos?

Ainda não possuímos respostas a essas indagações, mas estamos atentos ao "perigo" assinalado por Bein (2014, p. 89), de acreditarmos que somente o conhecimento de português, espanhol e línguas indígenas é suficiente para a construção de uma identidade latinoamericana. Tem razão este autor ao afirmar que somente uma política linguística não é suficiente para a criação de uma consciência comum sobre as relações neste continente. Entendemos que as ações orientadas ao ensino de línguas - a política linguística e até mesmo o planejamento linguístico - devem formar parte de um processo mais complexo, que envolva todo o sistema educativo, razão pela qual nos orientamos mais à perspectiva intercultural que à bilíngue no ensino de línguas.

\section{3. Últimas palavras: "Se hace camino al andar"}

Traçar o percurso realizado pela Língua Espanhola no sistema educacional brasileiro é, senão uma tarefa difícil, pelo menos surpreendente. Difícil porque, devido às dimensões de nosso território, cada região ou estado organizou a oferta deste idioma de acordo às suas possibilidades e surpreendente pela falta de planejamento e responsabilidade com os quais já foi inserido e, posteriormente, excluído.

Ao longo deste trabalho vimos que o caminho percorrido pelo idioma espanhol em nosso sistema educativo é bastante sinuoso. As diferentes percepções sobre o lugar que essa língua ocupa em relação ao português e a desatenção às especificidades locais, bem como a inadvertência sobre sua potencial capacidade de mediar relações interculturais, apontam a urgência na elaboração de propostas que incluam a diversidade de nosso território e o contato de nossas regiões fronteiriças com países hispano-falantes. 
Concluímos que, apesar dos esforços de profissionais na elaboração de uma proposta de inserção deste idioma no sistema educacional brasileiro, a realidade que vivemos continua sendo de incertezas. Do ano de 1942 (Reforma Capanema) ao ano de 2015 (ano em que se comemora o aniversário de 10 anos da assinatura da Lei 11.161) pouca coisa mudou: saímos do pré-construído sobre a língua fácil que não precisa ser estudada (Celada, 2002) à imposição da oferta (por parte das instituições de ensino e escolha facultativa por parte do corpo discente) sem avanços significativos que apontem, por exemplo, a consideração das especificidades regionais que influenciam e condicionam o ensino-aprendizado desse idioma.

\section{Referências}

ALMEIDA FILHO, J.C.P. Linguística Aplicada. Ensino de Línguas e Comunicação. 2. ed. Campinas: Pontes, 2007.

Dimensões comunicativas no ensino de línguas. 3ed. Campinas: Pontes, 2002.

ARNOUX, E. N.; NOTHSTEIN, S. Glotopolítica, integración regional sudamericana y panhispanismo. In: ARNOUX, E. N.; NOTHSTEIN, S. (Org.) Temas de glotopolítica. Integración regional sudamericana y panhispanismo. Ciudad Autónoma de Buenos Aires: Biblos, 2014, p. 9-29.

Representaciones sociolingüísticas y construcción de identidades colectivas en el Mercosur. In: CELADA, M. T.; FANJUL, A. P.; NOTHSTEIN, S. Lenguas en un espacio de integración: acontecimientos, acciones, representaciones. Ciudad Autónoma de Buenos Aires: Biblos, 2010, p. 17-38.

Desde Iguazú: mirada glotopolítica sobre la integración regional. In: FANJUL, A.P.; CASTELA, G. da S. (Orgs.) Línguas, políticas e ensino na integração regional. Cascavel, Gráfica Assoeste e Editora, 2011, p. 38-64.

BAUMAN, Z. Pensando sociológicamente. Buenos Aires: Nueva Visión, 1994.

BEIN, R. Políticas lingüísticas nacionales y de integración regional en América Latina. In: NARVAJA DE ARNOUX, E.; NOTHSTEIN, S. (Ed.) Temas de glotopolítica: Integración regional sudamericana y panhispanismo. $1^{\mathrm{a}}$ ed. Ciudad Autónoma de Buenos Aires: Biblos: 2014, p. 75-91.

BOHN, H. I. Os aspectos "políticos" de uma política de ensino de línguas e literaturas estrangeiras. Linguagem \& Ensino, Vol. 3, No 1, 2000, p. 117-138.

BRASIL. Orientações Curriculares para o Ensino Médio. Conhecimentos de Espanhol. Secretaria de Educação Básica. Brasília: Ministério de Educação, 2006, p.127-164. 
Lei 11.161, de 05 de agosto de 2005. Dispõe sobre o ensino da língua espanhola. Publicada no Diário Oficial da União, nº151, em 08 de agosto de 2005, s. 1, p.1.

Ministério da Educação. Parâmetros Curriculares Nacionais do Ensino Médio. Linguagens, códigos e suas tecnologias. Brasília: Secretaria de Educação Média e Tecnológica, 1998.

Secretaria de Educação Fundamental. Parâmetros Curriculares Nacionais: pluralidade cultural, orientação sexual. MEC/ SEF, 1997.

Lei 9.394, de 20 de dezembro de 1996. LDB/96. Estabelece as diretrizes e bases da educação nacional. Brasília: Ministério da Educação e Cultura.

CELADA, M. T. O espanhol para o brasileiro: uma língua singularmente estrangeira. Tese Doutorado. Departamento de Linguística, Campinas, 2002. Disponível em: <http://www.fflch.usp.br/dlm/espanhol/docente/teresa.html>. Acesso em: 3 maio 2007.

FANJUL, A. P. São Paulo: o pior de todos. Quem ganha e o que se perde com a (não) introdução do espanhol na escola pública paulista. In: CELADA, M. T.; FANJUL, A. P.; NOTHSTEIN, S. Lenguas en un espacio de integración: acontecimientos, acciones, representaciones. Ciudad Autónoma de Buenos Aires: Biblos, 2010, p. 185-207.

FREIRE, P. Educação como prática de liberdade. São Paulo: Paz e Terra, 2009.

HALL, S.; MELLINO, M. La cultura y el poder. Conversaciones sobre los cultural studies. Buenos Aires: Amorrortu, 2011.

JORGE, M. L. S. Preconceito contra o ensino de língua estrangeira na escola pública. In: LIMA, Diógenes (Org.). Ensino e aprendizagem de Língua Inglesa: conversa com especialistas. São Paulo: Parábola Editorial, 2009, p.161-168. (Estratégias de Ensino, 11).

MATOS, F. Apresentação. In: SEDYCIAS, J. (Org.). O ensino de espanhol no Brasil: passado, presente, futuro. São Paulo: Parábola Editorial, 2005, p.9-10. (Estratégias de ensino, $1)$.

PIZARRO, A. O sul e os trópicos. Ensaios de cultura latino-americana. Trad. Irene Kallina, Liege Rinaldi. Niterói: Editora da Universidade Federal Fluminense, 2006.

RIO GRANDE DO SUL. Secretaria de Estado da Educação. Departamento Pedagógico (Org.). Referenciais Curriculares do Estado do Rio Grande do Sul: Linguagens, Códigos e suas Tecnologias. $1^{\text {a }}$ ed. Porto Alegre: SE/ DP, 2009.

RODRIGUES, F. Língua viva, letra morta: obrigatoriedade e ensino de espanhol no arquivo jurídico e legislativo brasileiro. 2010. 342 p. Tese de doutorado, Universidade de São Paulo, Faculdade de Filosofia, Letras e Ciências Humanas. 